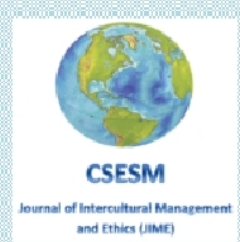

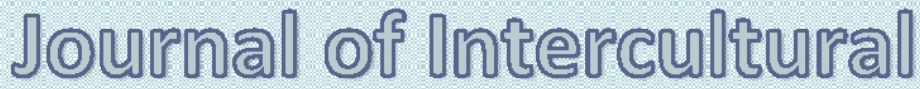

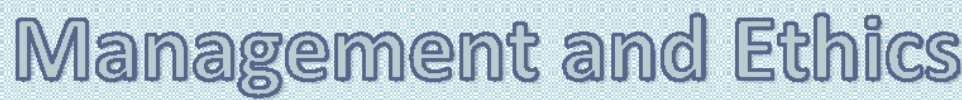

\author{
IOME
}

ISSN 2601 - 5749, ISSN-L 2601 - 5749

\section{published by zy \\ Center for Socio-Economic Studies and Multiculturalism \\ lasi, Romania \\ Waw csesmorg}




\section{Special Editor}

\section{Professor Beatrice Gabriela Ioan, PhD, MD}

Grigore T.Popa University of Medicine and Pharmacy of Iasi, Romania

E-mail: ioanbml@yahoo.com

\section{TABLE OF CONTENT}

Editorial

Beatrice Gabriela Ioan

Global Pandemics: Considerations of Public Health, Human Rights, and Bioethics

SanaLoue

Reactions of Bioethics to the Covid-19 Pandemic 19

Elena Toader, Luiza Palamaru, Tudor Stefan Rotaru, Oana Hrisca Eva

Implications of Cognitive-Behavioural Therapy in Changing Illness Representations .27

Ancuța Elena Păduraru, Camelia Soponaru

Healthcare Workers - Heroes and Villains in Covid-19 Pandemic. The Ethical

Communication

Ioana Silistraru

Ethical Dilemmas in the Therapeutic Management of Patients with Sars-Cov-2 Infection .. 45 Claudia Elena Pleşca, Ioana Hunea, Maria Obreja, Oana Stămăteanu, Delia Luchian, Irina Dima, Larisa Miftode, Tudorița Gabriela Părângă, Egidia Miftode, Simona Apostu, Camelia Bucur, Daniela Leca

Covid - 19 through the Window of Age 55

Elena Toader, Daniela Damir, Tudor Winzinger

Ethical Aspects of "Do Not Resuscitate" Orders in the Context of the Covid-19 Pandemic 61 Iulius Connor Gramma, Gema Bacoanu, Beatrice Gabriela Ioan

Ethics of the Human-Animal Relationship in the Covid-19 Pandemic .67

Cristin Coman, Diana Ancuta 


\title{
ETHICS OF THE HUMAN-ANIMAL RELATIONSHIP IN THE COVID-19 PANDEMIC
}

\author{
Cristin Coman ${ }^{1,2 *}$, Diana Ancuta ${ }^{2,3}$ \\ 1 "Spiru Haret" University, Faculty of Veterinary Medicine, Department of Ethics and \\ Laboratory Animal Science, Bucharest, Romania. \\ 2 „Cantacuzino" National Medico-Military Institute for Research and Development, \\ Preclinical Testing Unit, Bucharest, Romania. \\ 3 University of Agronomic Sciences and Veterinary Medicine, Faculty of Veterinary \\ Medicine, Preclinical Department, Bucharest, Romania. \\ *corresponding author, e-mail: comancristin@yahoo.com
}

\begin{abstract}
The ethics of the human-animal relationship, called animal ethics, is complex and depends on many factors (habits, education, and religion). Both components of animal ethics, the human-animal relationship and the way animals are treated by humans, were affected in this pandemic. Coronaviruses are common in many species of animals and can be transmitted from animals to humans as in COVID-19. After highlighting the initial cause of the disease as the virus transmission from animals to humans, many people suddenly gave up their pets abandoning them. Lockdown and loneliness have led to increased adoption of pets, but the occurrence of several cases of COVID-19 in them has quickly led to increased abandonment.

Another human action in this pandemic was the mass killing of animals suspected of transmitting the virus to humans, just like other diseases, the victims now being animals raised for fur. The race for COVID-19 treatments/vaccines has led to the creation of many experimental models from rodents to non-human primates. These studies have led to an increase in the acceptance by the population of the use of animals for scientific purposes but also to a degradation of the moral status of animals that have become laboratory instruments in reporting.

The analysis of animal ethics in the COVID-19 pandemic shows that the anthropocentric theory of the human-animal relationship dominates, and the relational theory of self-saving and those close to us is more current than ever. However, our relationship with animals must reconcile life veneration with the inevitability of killing them.
\end{abstract}

Keywords: Animal ethics, COVID-19, Animal coronaviruses, Pets, SARS-CoV-2, Anthropocentrism.

\section{Introduction}

The ethics of the human-animal relationship also called animal ethics is reflected in human-animal relationships, in the way people see the use of animals and thus influence their human action and behavior towards animals. Animal ethics may vary according to the perceived category or use of the animal in relation to the role of the harmful animal or parasite, pet or farm animal (Taylor \& Signal, 2005; Coeckelbergh \& Gunke, 2014).

Human attitudes towards animals are also influenced by phylogenetic distance, aesthetics and vulnerability (Serpell, 2004). Differences in the way humans view the moral value of animals will lead to different perceptions of how humans should treat animals. These 
differences sometimes lead to conflicting judgments about how humans should treat animals, the real needs of animals and the interests of the involved people. The evolution of science tends to give animals (especially mammals and some birds) cognitive abilities, a mental universe much higher than the mere assumption of being sensitive (Christen, 2010).

The extension of moral consideration to animals derives from the extension of moral theories that have been developed to regulate human activities and impose standards on actions and decisions that may affect other human beings. Therefore, we will find in the academic field an extension of the ethical theory of utilitarianism to all sentient beings and of the theories of rights inspired by Kantian deontology and community theses (Feinberg, 1978).

This article analyzes the attitude of humans towards animals during the COVID-19 pandemic, from the onset of disease through the transmission of SARS-CoV-2 virus from animals to humans to the use of animals for the scientific purpose of explaining the pathogenesis of the disease, developing new treatments, medical equipment and creating vaccines to immunize the population against the disease. The analysis is based on original scientific articles in English, articles found in the PubMed MEDLINE, Web of Science Core Collection and medRxiv/BioRxiv (preprint) databases up to January 2021. English-language press articles available on the internet were also studied.

Without claiming to be exhaustive, the article covers the main aspects of humananimal moral relations in COVID-19 pandemic.

\section{Transmission of COVID-19 virus from animals to humans}

Severe acute respiratory syndrome coronavirus 2 or SARS-CoV-2 is the causative agent of the disease called Coronavirus 2019 (COVID-19), first described in China, Wuhan, at the end of 2019 (Wu et al., 2020). The disease has spread rapidly globally, causing significant morbidity and mortality, so that in March 2020, the World Health Organization declared COVID-19 a pandemic (Cucinotta \& Vanelli, 2020).

Coronaviruses are common in several species of domestic and wild animals, including cattle, horses, dogs, cats, ferrets, camels, bats, etc. Coronaviruses can be transmitted from animals to humans (e.g. SARS-CoV, MERS-Co-V and now SARS-CoV-2). The primary reservoir of the virus is the bat (Rhinolophus affinis), but the transmission to humans was made through intermediate hosts, cat-civet at SARS-CoV, camel dromedary at MERS-CoV and pangolin at SARS-CoV-2.

In SARS-CoV, the virus was transmitted from bat to civet, and the consumption of this animal and its handling led to the appearance of the disease in the human population. Dr. Carlo Urbani, who was at the beginning of the pandemic at its outbreak, alerted the World Health Organization (WHO) and the rapid intervention of this organization caused the pandemic to have only 800 victims (Fleck, 2003).

In the case of SARS-CoV-2, it seems that the natural reservoir is also the bat (Zhou et al., 2020). People in Wuhan caught live bats in caves near the city, where bats hibernated in November. The bats were taken to the live animal market in Wuhan, where they were kept in cages near the pangolins and in this way the virus could spread to the pangolins, or there was an epidemic of disease among bats, and the pangolins fed on insects on their corpses. The pangolin is an endangered, scaly skin placental mammal that feeds on ants and is appreciated by the Chinese for meat, but especially for scales used in traditional medicine on a large scale as an aphrodisiac. Transmission to early cases was most likely through contact with live animals sold in markets and/or consumption and handling of processed meat, but also through handling and processing of scales. The virus can be found in feces, urine and meat and therefore it was possible to transmit it to those who handle it without caution. If this occurrence is natural, it is closely linked to several factors, especially ecological: human activity and probably trade in wild animals that allowed human exposure to the virus. The 
virus is thought to be of animal origin because it has been shown to have a $96.2 \%$ identity with a bat virus strain called Bat CoVRaTG13 and a pangolin coronavirus, and a recombination between coronaviruses of these 2 animal species would have generated the new coronavirus (Wrobel et al, 2020; Dimonaco, Salavati \& Shih, 2020).

Although it is still difficult to determine exactly how this initial contact was made between humans and animals carrying the SARS-CoV-2 coronavirus, however, there has been an exponential and rapid increase in the last quarter of the twentieth century of zoonosis. There is a strong correlation between this phenomenon and the number of threatened bird and mammal species according to the criteria of The International Union for Conservation of Nature Red List of Threatened Species - IUCN (Morand, Owers \& Bordes, 2014). Research suggests that the pressures exerted by these anthropogenic activities on biodiversity, in particular the overexploitation of living resources (including poaching), the fragmentation and rapid reduction of natural habitats leading to a collapse of animal and plant populations and a significant loss of genetic diversity and phylogenetic are at the origin and multiplication of these zoonosis (Morand, Jittapalapong, Suputtamongkol, Abdullah \& Huan, 2014).

Over $70 \%$ of diseases are common to humans and animals, and the health of the environment, water, air and soil is directly related to human health. Globalization and easy access to fast travel have made cross-border diseases a major concern for food safety and food security. Unsustainable human activities, natural disasters (fires and floods), create pathways for the formation and spread of pathogens, chemicals and other pollutants that contaminate the air, water and environment in which we live and produce food. In the last three decades, about $75 \%$ of new human infectious diseases have been zoonotic.

The global population has exceeded 8 billion people and is estimated at approximates 30 billion animals are raised annually to provide food for this population (Food and Agriculture Organization of the United Nations, 2016).

However, now responsible for the faster spread of the virus, which has led to the current ongoing pandemic is human-to-human transmission.

\section{Pet and Farm animals}

With the development of the middle class and urbanization, the habit of owning a pet spread throughout the world. People began to speak in a positive way about animal intelligence. At the same time, the idea spread that animals could have character and personality and the psychological foundations were laid for the conception that some animals are entitled to a greater moral consideration (Keith, 1983).

After the confirmation of COVID-19 disease, the declaration of the pandemic and the highlighting of the probable main cause of the disease as the transmission of the virus from animals to humans, many people, gave up their pets abruptly and without reason, including stray animals (Thomson, 2020; Ho, 2020).

The imposed lockdown and the accompanying loneliness have especially led to an increase in the number of adoption of dogs and cats in Europe (Fox, 2020). Owning a pet improves the physical and mental condition of the owner, but also brings greater responsibilities (Powell et al., 2019; Ratschen et al., 2020). However, the emergence of several cases of COVID-19 in dogs and cats from Hong Kong to the USA has quickly led to a halt in adoptions and even an increase in dropouts (Parry, 2020).

Although specialists have shown that animals have become ill from their owners and that the increased anthropomorphizes of pets will continue to lead to the transmission of diseases from humans to animals, the excessive popularization of these cases and the fear of death has led to the massive removal of pets and their abandonment. The fact that people returned to work after lockdown and realized that the responsibility they have when owning an animal is quite high has also contributed to the abandonment of animals (Fox, 2020). 
Although the zoonotic origin of COVID-19 is almost certain, only one case of human contamination by animals by SARS-CoV-2 has been documented on a mink farm in the Netherlands, and there is currently no evidence that animals are involved in the spread of the pandemic in the human population (Oreshkova et al., 2020; Oude Munnink et al., 2021). On the other hand, human-animal contamination by SARS-CoV-2 has been described several times: since the first case on February 26 of the dog infected by its owner in Hong Kong, other cases have been reported in the same city ( 2 dogs and a cat), as well as in Belgium (a cat), in the United States ( 5 tigers, 3 lions, 7 dogs, 5 cats), in France (2 cats), in Spain ( 2 cats, a mink farm), Germany (one cat), Russia (one cat), the Netherlands (25 mink farms) and Denmark (3 mink farms) as in January 2021. A serological study in Wuhan after the Covid19 epidemic showed that of 102 cats tested, 11 were infected (Zhang et al., 2020). In France, 9 cats and 12 dogs in close contact with 20 veterinary students with COVID-19 (suspected or confirmed) remained COVID-19 negative. In addition, COVID-19 - positive cats were found near Dutch mink farms ( 3 cats out of 11 on a farm and 7 stray cats out of 24 near two infected farms, these 24 stray cats did not enter homes) (Oreshkova et al., 2020). However, the transmission of the disease between animals is possible, as shown by a study in which infected cats transmit the disease to uninfected cats (Halfmann et al., 2020).

Except in the particular case of the mink farm in the Netherlands, where the spread of the virus by aerosols, favored by a high density of animals inside animal shelters, rapidly infected the vast majority of minks, as well as two employees, none of these observations it currently allows us to conclude that SARS-CoV-2 is contagious from animal to human or from animal to animal. Moreover, there are no data in favor of transmitting the virus to wild animals under natural conditions.

In order to avoid the contamination of animals by humans, but also to avoid the abandonment of pet animals, agencies such as the Centers for Disease Control (CDC) have developed several protocols for the care and contact with animals (Centers for Disease Control, 2021).

In recent decades, public opinion has shown a growing concern about the overindustrialization of farmed animals and their welfare (The American Society for the Prevention of Cruelty to Animals, 2020). There are also concerns about the spread of zoonosis through these farms (Jones et al., 2013).

During the pandemic, concerns increased, both against the background of possible illness of workers, but also to the reduction in animal care, the press reports being numerous in this regard (Frerick \& Mitchell, 2020; Gawthorpe, 2020). The pandemic and lockdown with closing restaurants, reducing travel has caused the meat market to collapse. Many slaughterhouses were closed; farmers no longer had a place to slaughter their animals, being forced to kill them on their farms (Polansek \& Huffstutter, 2020).

Another human action related to animals in this pandemic was the mass killing of animals suspected of transmitting the virus to humans, just as in the case of bird flu and swine flu. The victims this time were animals raised for the production of fur, nutria and mink. Tens of thousands of fur animals have been euthanized in farms in the Netherlands, Spain, France (Koopmans, 2020), the most shocking action being in Denmark. As many as 17 million minks have been killed in masse and buried in mass graves on army grounds after the Danish government announced that a coronavirus mutation had been reported, raising fears that it could be transmitted to humans or could compromise the vaccination action (Oxner, 2020). The country's prime minister later said there was no evidence of a human mutation, and acknowledged that there had been no sick mink in Denmark since September, although authorities ordered the killing of millions of animals a month later in October (Murray, 2020). One of these viruses has four mutations in its Spike protein. This was demonstrated in laboratory tests in people who contracted Covid-19. But the virus itself is no more dangerous 
or contagious. Danish scientists feared that the mutant virus called 'cluster 5' has the potential to make future vaccines less effective (Lassaunière et al., 2020). In addition, according to the WHO, in 214 cases of people with COVID-19 were identified in Denmark with variants associated with farmed mink in June, hence this eradication decision taken by Danish authority (WHO, 2020). "We prefer to take one measure too much rather than one less," said the head of the Danish Diplomacy (Suliman, 2020). All these actions in the fight against Covid-19 and limiting the spread of the disease to humans highlight on the one hand excessive and sometimes hasty actions of humans on animals, and on the other hand the fact that the industrialization of animal husbandry for meat and fur production must be closely monitored paying much more attention to animal welfare.

\section{Animals used for scientific purposes}

At the time of COVID-19 pandemic, the entire scientific community in the world mobilized in researching the pathogenesis of this disease, in identifying treatments, in discovering vaccines, in evaluating new medical equipment and devices, etc. One of the tools used was the laboratory animal, the pandemic showing the importance and necessity of animal studies (Genzel et al., 2020). Benefiting from the results of SARS-CoV research on animals, new ways, new methods, new molecules were sought that can stop the evolution and spread of COVID-19. The new pandemic rules, the urgency and the need for rapid results have allowed animal studies to be carried out without following the complex procedures that follow an animal experiment, namely ethical evaluation and authorization of studies by the competent authority, procedures that could last up to 3 months. Rapid evaluations have replaced complex evaluations. The results obtained made the population have a wider acceptance of animal experiments. However, this excessive use has also led to an instrumentalism of the laboratory animal and its discretionary use by humans, the animals being considered as laboratory reagents similar to chemical and immunological reagents, which raises ethical issues requiring other approaches (Fenton \& Johnson, 2020). Based on published studies, animal models of SARS-CoV and MERS-CoV include civet cats, camelids, non-humans primates, mice, hamsters, ferrets, rabbits and other potential hosts (Roberts et al., 2008). With regard to SARS-CoV-2, the main model animals were mice and non-human primates, especially the rhesus macaque. Cat models may be quite useful for understanding the shed/spread kinetics of SARS-CoV-2 (Bosco-Lauth et al., 2020). Extensive studies have also been performed on hamster, ferret, dog, pig, and animal models suitable for COVID-19 are still sought (Lakdawala \& Menachery, 2020). Studies on COVID-19 are numerous, so the Cochrane study register for Covid-19 listed on 23 January 2021 more than 40000 studies launched, with 4423 of them being interventional (Cochrane-COVID-19, 2021). At the same date there were 11 vaccines approved in different countries, 78 candidate vaccines and 201 vaccines at different stages of development (McGill COVID19 Vaccine Tracker Team, 2021) all requiring in one form or another animal studies, even if the results can sometimes be false or even controversial (Deb, Shah \& Goel, 2020). However, there are also studies and attempts to replace animals in these experimental studies current technology allowing scientific advances without the use of animals (Busquet, Hartung, Pallocca, Rovida $\&$ Leist, 2020) some of which can be used in the COVID-19 pandemic (Si et al., 2020). All these efforts show that the replacement of animals in biomedical experimentation can be achieved in the future.

\section{Conclusions}

The ethics of the relationship between humans and animals in the COVID-19 pandemic, manifested by various actions, showed that the anthropocentric theory of animal 
use in favor of man dominates, and the relational theory of personal saving and loves one is more current than ever.

However, strengthening the moral status of animals and our relationship with animals must reconcile veneration with life with the inevitability of using and harm sometimes animals and increase the quality of life of animals through education and legislation.

\section{References}

Bosco-Lauth, A., M., Hartwig, A., E., Porter, S., M., Gordy, P., W., Nehring, M., Byas, A., D....Bowen, R. A. (2020). Experimental infection of domestic dogs and cats with SARS-CoV-2: Pathogenesis, transmission, and response to reexposure in cats. Proceedings of the National Academy of Sciences, PNAS first published September 29, 2020. https://doi.org/10.1073/pnas.2013102117.

Busquet, F., Hartung, T., Pallocca, G., Rovida, C. \& Leist, M. (2020). Harnessing the power of novel animal-free test methods for the development of COVID-19 drugs and vaccines. Archives of Toxicology, 94, 2263-2272. doi: 10.1007/s00204-020-02787-2.

Centers for Disease Control. (2021). COVID-19 and Animals. Retrieved from https://www.cdc.gov/coronavirus/2019-ncov/daily-life-coping/animals.html.

Christen, Y. (2010). Is an animal a person? And are scientists always rational animals?. Biologie aujourd'hui, 204, 235-242. doi:10.1051/jbio/2010012.

Cochrane-COVID-19 (2021, January). Study register. Retrieved from https://covid19.cochrane.org/.

Coeckelbergh, M. \& Gunke, D., J. (2014). Facing Animals: A Relational, Other-Oriented Approach to Moral Standing. Journal of Agricultural and Environmental Ethics, 27, 715-733. doi: 10.1007/s10806-013-9486-3.

Cucinotta, D., \& Vanelli, M. (2020). WHO Declares COVID-19 a Pandemic. Acta BioMedica, 91(1), 157-160. doi: 10.23750/abm.v91i1.9397.

Deb, B., Shah, H. \& Goel, S. (2020). Current global vaccine and drug efforts against COVID19: Pros and cons of bypassing animal trials. Journal of Biosciences, 45( 1), 1-10. doi: 10.1007/s12038-020-00053-2.

Dimonaco, N., J., Salavati, M. \& Shih, B. (2020) Hacking the Diversity of SARS-CoV-2 and SARS-Like Coronaviruses in Human, Bat and Pangolin Populations. bioRxiv (preprint). https://doi.org/10.1101/2020.11.24.391763.

Feinberg, J. (1978). Human Duties and Animal Rights. In Feinberg, J, 1980 (eds.), Rights, Justice and the Bounds of Liberty (185-202). Princeton, NJ: Princeton University Press.

Fenton, A. \& Johnson, L., S., M. (2020). COVID-19 Animal Research Reveals Ethical Shortcomings. Impact Ethics. Retrieved from https://impactethics.ca/2020/09/25/covid-19-animal-research-reveals-ethicalshortcomings/.

Fleck F. (2003). Carlo Urbani. British Medical Journal, 326(7393), 825. PMCID: PMC1125733.

Food and Agriculture Organization of the United Nations. (2016). The state of food and agriculture: Climate change, agriculture and food security. Rome. Retrieved from http://www.fao.org/3/a-i6030e.pdf.

Fox, R. (2020, august). Has COVID-19 changed our relationship with pets and other animals? Warwick Knowledge Center. Retrieved from https://warwick.ac.uk/newsandevents/knowledgecentre/society/sociology/animals_an d_covid19.

Frerick, A. \& Mitchell, C. (2020, April). Multinational Meat Farms Could Be Making Us Sick. The American Conservative. Retrieved from 
https://www.theamericanconservative.com/articles/multinational-meat-companiescould-be-making-us-sick/.

Gawthorpe, A. (2020, August). The pandemic highlights the gruesome animal abuses at US factory farms. The Guardian. Retrieved from

https://www.theguardian.com/commentisfree/2020/aug/03/coronavirus-animal-abuseus-factory-farms.

Genzel, L., Adan, R., Berns, A., van den Beucken, J., J., P., Blokland, A., Boddeke, E.

H.W.G.M Homberg, J., R. (2020). How the COVID-19 pandemic highlights the necessity of animal research. Current Biology, 30(18), R1014-R1018, doi:10.1016/j.cub.2020.08.030.

Halfmann, P., J., Hatta, M., Chiba, S., Maemura, T., Fan, S. Takeda, M .Kawaoka, Y. (2020). Transmission of SARS-CoV-2 in Domestic Cats, New England Journal of Medicine, 383(6), 592-594, doi: 10.1056/NEJMc2013400.

Ho, S. (2020, February). Pets Are Being Killed In China Due To Coronavirus

Misinformation. Green Queen, https://www.greenqueen.com.hk/pets-are-being-killedin-china-due-to-coronavirus-misinformation/

Jones, B. A., Grace, D., Kock, R., Alonso, S., Rushton, J., Said, M., Y... Pfeiffer, D., U. (2013). Zoonosis emergence linked to agricultural intensification and environmental change. Proceedings of the National Academy of Sciences of the United States of America, 110. 21. 8399-8404. https://doi.org/10.1073/pnas.1208059110.

Keith, T. (1983). Man and the Natural World: Changing Attitudes in England 1500-1800. London, UK: Penguin (1991 eds.).

Koopmans, M. (2020). SARS-CoV-2 and the human-animal interface: outbreaks on mink farms. The Lancet Infectious Diseases, 21(1), 18-19. doi: 10.1016/S14733099(20)30912-9.

Lakdawala, S., S. \& Menachery, V., D. (2020). The search for a COVID-19 animal model. Science, 368, 6494, 942-943. doi: 10.1126/science.abc6141.

Lassaunière, R., Fonager, J., Rasmussen, M., Frische, A., Strandh, C., P., Rasmussen, T., B....Fomsgaard, A. (2020). SARS-CoV-2 spike mutations arising in Danish mink and their spread to humans. Department of Virus and Microbiological Special Diagnostic, Statens Serum Institut, Copenhagen, Denmark. Retrieved from https://files.ssi.dk/Mink-cluster-5-short-report_AFO2.

McGill COVID19 Vaccine Tracker Team.(2021, January). COVID-19 vaccine Tracker. Retrieved from https://covid19.trackvaccines.org/.

Morand S., Jittapalapong S., Suputtamongkol Y., Abdullah M.,T. \& Huan T., B. (2014), Infectious Diseases and Their Outbreaks in Asia-Pacific: Biodiversity and Its Regulation Loss Matter. PLOS ONE, 9(2). doi:_10.1371/journal.pone.0090032.

Morand S., Owers K., \& Bordes F. (2014) Biodiversity and Emerging Zoonoses. In: Yamada A., Kahn L., Kaplan B., Monath T., Woodall J., Conti L. (eds.) Confronting Emerging Zoonoses (27-41). Tokyo, Japan: Springer. https://doi.org/10.1007/978-4-431-55120$1 \_3$.

Murray, A. (2020, November). Coronavirus: Denmark shaken by cull of millions of mink. $B B C$ News. Retrieved from https://www.bbc.com/news/world-europe-54890229.

Oreshkova, N., Molenaar, R., J., Vreman S., Harders, F., Oude Munnink, B., B., Hakze-van der Honing, R., W, Stegeman, A. (2020). SARS-CoV-2 infection in farmed minks, the Netherlands, April and May 2020. EuroSurveillance, 25(23). Doi:10.2807/15607917.ES.2020.25.23.2001005

Oude Munnink, B., B., Sikkema1, R., S., Nieuwenhuijse, D., F., Molenaar, R., J., Munger, E., Molenkamp, R., Koopmans, M., P., G. (2021). Transmission of SARS-CoV-2 on 
mink farms between humans and mink and back to humans. Science, 371, 6525, 172177. doi: 10.1126/science.abe5901.

Oxner, R. (2020, November). Denmark to Kill Up To 17 Million Minks after Discovering Mutated Coronavirus. NPR. Retrieved from https://www.npr.org/2020/11/05/931726205/denmark-to-kill-up-to-17-million-minksafter-discovering-mutated-coronavirus? $\mathrm{t}=1611551393993$.

Parry N. (2020). COVID-19 and pets: When pandemic meets panic. Forensic Science International: Reports, 2, 100090. doi:10.1016/j.fsir.2020.100090

Polansek, T., \& Huffstutter, P., J. (2020, April). Piglets aborted, chickens gassed as pandemic slams meat sector. Thomson Reuters. Retrieved from https://www.reuters.com/article/us-health-coronavirus-livestock-insight/pigletsaborted-chickens-gassed-as-pandemic-slams-meat-sector-idUKKCN2292YS.

Powell, L., Edwards, K., M., McGreevy, P., Bauman, A., Podberscek, A., Neilly B. \& Stamatakis, E. (2019) Companion dog acquisition and mental well-being: a community - based three-arm controlled study. British Medical Journal Public Health 19, (1):1428. doi:_10.1186/s12889-019-7770-5.

Ratschen E., Shoesmith E., Shahab L., Silva K., Kale, D, Toner, P. ...Mills, D. (2020). Human-animal relationships and interactions during the Covid-19 lockdown phase in the UK: Investigating links with mental health and loneliness. PLOS ONE, 15(9): e0239397. doi:10.1371/journal.pone.0239397.

Roberts, A., Lamirande, E., W., Vogel, L., Jackson, J., P., Paddock, C., D., Guarneret, J. Subbarao K. (2008). Animal models and vaccines for SARS-CoV infection. Virus Research, 133 (1), 20-32. doi: 10.1016/j.virusres.2007.03.025.

Serpell, J.A. (2004). Factors influencing human attitudes to animals and their welfare. Animal Welfare, 13 (S1), 145-151. Retrieved from

https://www.researchgate.net/profile/James_Serpell/publication/263077760_Factors_I nfluencing_Human_Attitudes_to_Animals_and_Their_Welfare/links/5ad76931aca27 2fdaf7ed77b/Factors-Influencing-Human-Attitudes-to-Animals-and-TheirWelfare.pdf.

Si, L., Bai, H., Rodas, M., Cao, W., Oh, C., Y., Jiang, A. Ingber, D., E. (2020). Human organs-on-chips as tools for repurposing approved drugs as potential influenza and COVID19 therapeutics in viral pandemics. bioRxiv (preprint) 2020.04.13.039917; doi: 10.1101/2020.04.13.039917.

Suliman, A. (2020, November). Denmark vows to kill millions of minks even after WHO downplays COVID mutation risk. NBC News. Retrieved from https://www.nbcnews.com/news/world/who-downplays-coronavirus-mink-mutationrisk-after-denmark-orders-huge-n1246726

Taylor, N. \& Signal, T., D. (2005) Empathy and attitudes to animals, Anthrozoös, 18(1), 1827, doi: 10.2752/089279305785594342.

The American Society for the Prevention of Cruelty to Animals. (2020). 2020 Survey on COVID-19's Impact on Public Attitudes toward Factory Farming. Retrieved from https://www.aspca.org/shopwithyourheart/business-and-farmer-resources/aspcasurveys.

Thomson, B. (2020, February). Chinese officials 'round up and execute villagers' pets to stop the spread of coronavirus' despite WHO experts saying the disease cannot be spread to animals. MailOnline. https://www.dailymail.co.uk/news/article-8024787/Chineseofficials-continue-beat-dogs-death-fighting-coronavirus.html.

World Health Organization. (2020, November). SARS-CoV-2 mink-associated variant strain - Denmark. Retrieved from https://www.who.int/csr/don/06-november-2020-minkassociated-sars-cov2-denmark/en/. 
Wrobel, A.G., Benton, D.J., Xu, P., Roustan, C., Martin, S., R., Rosenthal, P., B., Gamblin, S. (2020). SARS-CoV-2 and bat RaTG13 spike glycoprotein structures inform on virus evolution and furin-cleavage effects. Nature Structural \& Molecular Biology, 27, 763-767. Doi: 10.1038/s41594-020-0468-7.

Wu, F., Zhao, S., Yu, B., Wang, W., Song Z.-G., Hu Y., Zhanget Y.-Z. (2020). A new coronavirus associated with human respiratory disease in China. Nature, 579, 265 269. doi:org/10.1038/s41586-020-2008-3.

Zhang, Q., Zhang, H., Huang, K., Yang, Y., Hui, X., Gao, J... Jin, M. (2020, April). SARSCoV-2 neutralizing serum antibodies in cats: a serological investigation. bioRxiv (preprint) 2020.04.01.021196. doi:10.1101/2020.04.01.021196.

Zhou, P., Yang, X.-L., Wang, X.-G., Hu B., Zhang L., Zhang W., Si H.-R.,.... Shi, Z-L. (2020). A pneumonia outbreak associated with a new coronavirus of probable bat origin. Nature, 579, 270-273. doi:10.1038/s41586-020-2012-7. 